Gest, H. \& Honowitz, N. H. (1958). J. gen. Microbiol. 18, 64-70

\title{
Activation and Thermostability of Neurospora crassa Tyrosinase
}

\author{
By H. GEST* AND N. H. HOROWITZ \\ Kerckhoff Laboratories of Biology, California Institute of Technology, Pasadena, \\ California, U.S.A.
}

SUMMARY: Tyrosinase in crude cell-free preparations from two strains of Neurospora crassa is markedly activated by gentle heating or by exposure to sodium ion, urea, or certain organic nitrogenous bases. The tyrosinase activity of non-activated extracts increases during assay, whereas activated enzyme displays the 'reaction inactivation' kinetics characteristic of many copper oxidases. Activation by $\mathrm{Na}^{+}$is antagonized by $\mathrm{K}^{+}$and is readily reversible. Urea activation is also reversible, but the activation due to heating appears to be irreversible. The thermostability of tyrosinase derived from strain $\mathrm{T}^{\mathrm{\beta}}$ is increased greatly by $\mathrm{Na}^{+}$(and less effectively by $\mathrm{K}^{+}$) and the half-life of thermal inactivation at $59^{\circ}$ varies between wide limits, depending on the ionic environment. The relatively heat-labile tyrosinase of strain $\mathbf{T}^{\mathrm{L}}$ shows qualitatively similar behaviour but is quantitatively different with regard to stabilization by $\mathrm{Na}^{+}$and $\mathrm{K}^{+}$.

Most strains of Neurospora crassa produce tyrosinase during vegetative growth, and previous studies from this laboratory (Horowitz \& Fling, 1953, $1956 a, b)$ have shown that the enzyme occurs in two forms which differ markedly in thermostability. The half-lives of thermal inactivation of the two forms at $59^{\circ}$ in $0.1 \mathrm{M}$-phosphate buffer $\mathrm{pH} 6$ have been reported to be 3 and 70 min., respectively (Horowitz \& Fling, 1953). Genetic analysis indicates that the thermostability property is determined by a pair of Mendelian alleles, designated as $\mathbf{T}^{\mathbf{L}}$ (thermolabile) and $\mathrm{T}^{\mathrm{s}}$ (thermostable) (Horowitz \& Fling, 1953). The present report is concerned with 'activation' of the cell-free tyrosinases of the $T^{\mathbf{L}}$ and $\mathrm{T}^{\mathrm{s}}$ strains and with the influence of chemical factors on the thermostability property.

\section{METHODS}

Neurospora crassa strains 4-137a $\left(\mathrm{T}^{\mathrm{L}}\right)$ and 4-121 A $\left(\mathrm{T}^{\mathbb{8}}\right)$ were grown for 4 days at $25^{\circ}$ in the 'low sulphur' minimal medium described by Horowitz $\&$ Shen (1952), with the exceptions that the carbon source was $1.5 \%$ glucose and ammonium nitrate was omitted. To prepare cell-free extracts, the harvested mycelium was thoroughly washed with water, ground with sand $(0.5 \mathrm{~g} / \mathrm{g}$. moist mycelium), and the mixture extracted with approximately $10 \mathrm{vol}$. of water. After a preliminary centrifugation to remove sand and cell debris, the extracts were recentrifuged for at least $1 \mathrm{hr}$. in the International Refrigerated Centrifuge $(c .20,000 \mathrm{~g})$ or in the Spinco Centrifuge $(c .140,000 \mathrm{~g})$.

* Present address: The Department of Microbiology, Western Reserve University School of Medicine, Cleveland, Ohio, U.S.A. 
For the experiments summarized in Table 3, the organisms were grown and the partially purified tyrosinases prepared as described by Horowitz \& Fling (1953).

Tyrosinase activity was determined colorimetrically, essentially as described by Horowitz \& Shen (1952), using DL-3: 4-dihydroxyphenylalanine as the substrate. In this procedure, activity is measured in terms of optical density increase (expressed as colorimeter units) due to 'dopachrome' formation, determined in the Klett-Summerson photoelectric colorimeter using a no. 42 blue filter. The 'mixed' $0 \cdot 1$ м (pH 6) phosphate buffer used for the experiments of Fig. 1. and Table 3 was composed of $0.088 \mathrm{M}-\mathrm{KH}_{2} \mathrm{PO}_{4}$ and $0 \cdot 012 \mathrm{M}-\mathrm{Na}_{2} \mathrm{HPO}_{4}$.

\section{RESULTS}

\section{Activation of tyrosinase}

Typical results showing the effect of a short heat treatment on tyrosinase activity in crude extracts of Neurospora crassa ( $T^{\mathrm{s}}$ strain) are shown in Fig. 1. Curve $B$ represents the course of the reaction observed with untreated extract, while curve $\boldsymbol{A}$ illustrates the activity observed with extract preheated at

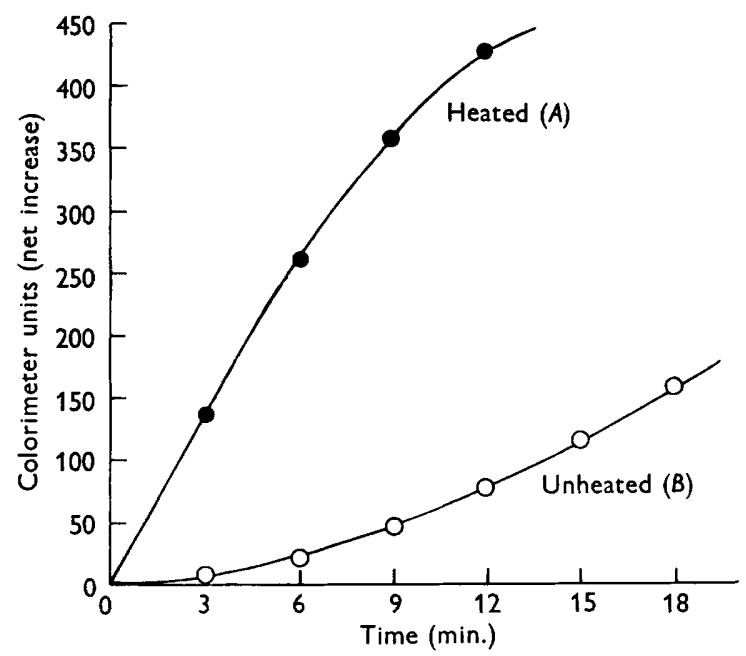

Fig. 1. Effect of preheating at $59^{\circ}$ for $1.5 \mathrm{~min}$. on the activity of $\mathrm{T}^{\mathrm{s}}$ tyrosinase. Curve $\boldsymbol{A}$ : extract was diluted twofold with water, heat treated, and the activity of a $0.08 \mathrm{ml}$. aliquot measured (in 'mixed' $0 \cdot 1 \mathrm{M}$-phosphate buffer $\mathrm{pH}$ 6). In order to facilitate direct comparison with the activity shown by $0.2 \mathrm{ml}$. of unheated extract (curve $B$ ), the observed increases in optical density were multiplied by 5 to give the points indicated. Curve $B$ : activity of $0 \cdot 2 \mathrm{ml}$. unheated extract in $0 \cdot 1 \mathrm{M}$-phosphate buffer pH 6 .

$59^{\circ}$ for $1.5 \mathrm{~min}$. It is evident that the short heat treatment increased the activity markedly, and it may be noted that the activated preparation shows the type of kinetics frequently observed with copper enzymes such as ascorbic acid oxidase or mushroom tyrosinase, i.e. a rapid decrease in activity during the course of the reaction, which is usually referred to as 'reaction inactivation' (Dawson \& Tarpley, 1951). The unheated preparation, on the other hand, 
shows a gradual increase in activity, presumably due to activation occurring during the assay. Extracts of strain $\mathbf{T}^{\mathrm{L}}$ showed the same behaviour.

The thermal activation appears to be irreversible. It is of interest that the activity of partially purified Neurospora crassa tyrosinase is usually not increased by short-term heating (Horowitz \& Fling, 1953), apparently because activation occurs during the purification procedure.

It was observed that the tryosinase in both $\mathrm{T}^{\mathrm{s}}$ and $\mathrm{T}^{\mathrm{L}}$ extracts can also be fully activated by addition of sodium ion. The activation due to $\mathrm{Na}^{+}$is antagonized by $\mathrm{K}^{+}$as shown in Table 1 . In the absence of added $\mathrm{K}^{+}$, a relatively low concentration of $\mathrm{Na}^{+}$effectively activates the enzyme. With a

Table 1. Activation of Neurospora crassa tyrosinase by sodium ion

$\begin{array}{ccccc}\text { Tube no. } & \overbrace{\begin{array}{c}\text { Na succinate } \\ (\text { ml. })\end{array}}^{\text {Buffer* }} & \begin{array}{c}\text { K succinate } \\ (\mathrm{ml})\end{array} & \begin{array}{c}\text { Na succinate/ } \\ \text { K succinate }\end{array} & \begin{array}{c}\text { Initial activity } \\ \text { (colorimeter units) }\end{array} \\ 1 & 4 \cdot 4 & - & - & 132 \\ 2 & 0 \cdot 9 \dagger & - & - & 126 \\ 3 & 0 \cdot 4 \dagger & - & - & 118 \\ 4 & 4 \cdot 0 & 0 \cdot 4 & 10 & 99 \\ 5 & 3 \cdot 0 & 1 \cdot 4 & 2 \cdot 14 & 61 \\ 6 & 1 \cdot 4 & 3 \cdot 0 & 0 \cdot 47 & 36 \\ 7 & 0 \cdot 4 & 4 \cdot 0 & 0 \cdot 1 & 28 \\ 8 & - & 4 \cdot 4 & - & 21\end{array}$

In each case, $0 \cdot 1 \mathrm{ml}$. of a water extract of $T^{\mathrm{s}}$ was mixed with buffer; after equilibration at $30^{\circ}$ for 2.5 to $3.5 \mathrm{~min}$., $0.5 \mathrm{ml}$. of $0.02 \mathrm{M}$ DL-3,4-dihydroxyphenylalanine was added and the activity determined during the first measurable $3 \mathrm{~min}$. interval.

${ }^{*} \mathrm{pH} 6.0$ and $0.05 \mathrm{M}$ with respect to succinate.

$\dagger$ Supplemented with water to a volume of $4.4 \mathrm{ml}$.

large excess of $\mathrm{Na}^{+}$, the reaction kinetics observed were qualitatively similar to those shown in curve $\boldsymbol{A}$ (Fig. 1), whereas with a large excess of $\mathrm{K}^{+}$a gradual increase in rate occurred. As might be expected, the kinetic curves for intermediate mixtures were complex, but in general they reflected the effect of the predominant cation. The antagonism observed between $\mathrm{Na}^{+}$and $\mathrm{K}^{+}$suggests that the $\mathrm{Na}^{+}$effect is reversible and this was confirmed in experiments in which a large excess of $\mathrm{K}^{+}$was added following activation by $\mathrm{Na}^{+}$- the resulting depressed activity was the same as that shown by enzyme added at zero time to a buffer containing previously mixed sodium and potassium succinates in the same ratio. Tyrosinase inhibited by excess $\mathrm{K}^{+}$can be fully activated by gentle heating (see Fig. 1).

Neurospora crassa tyrosinase can also be activated (reversibly) by c. $3 \mathrm{M}$ urea and tests with tris 2-amino-2-hydroxymethylpropane-1:3-diol and triethylaminesuccinate buffers $(\mathrm{pH}$ 6) showed that these nitrogenous bases also effected complete activation.

\section{Thermostability experiments}

The half-lives of thermal inactivation of crude $T^{\mathrm{s}}$ tyrosinase at $59^{\circ}$ in various pH 6 buffers are summarized in Table 2. In all instances, first-order inactivation kinetics were observed. From these data it can be seen that $\mathrm{Na}^{+}$ 
Table 2. Thermostability of crude $T^{s}$ tyrosinase at $59^{\circ}$ in various buffers at $\mathrm{pH} 6$

\begin{tabular}{|c|c|c|}
\hline Exp. & $\infty$ & $\begin{array}{c}\text { Half-life } \dagger \\
\text { at } \mathbf{5 9}^{\circ} \\
\text { (min.) }\end{array}$ \\
\hline $1 \ddagger$ & Na succinate & 67 \\
\hline 2 & Na succinate & 47 \\
\hline 3 & Na succinate ( 3 parts) $+K$ succinate ( 1 part) & 51 \\
\hline 4 & Na succinate ( 1 part) $+K$ succinate ( 3 parts) & 34 \\
\hline $5+$ & K succinate & $11 \cdot 5$ \\
\hline 6 & K succinate & 8 \\
\hline 7 & Tris-succinate & $\mathbf{2 \cdot 5}$ \\
\hline 8 & Triethylamine-succinate & $c .1$ \\
\hline
\end{tabular}

* In Exps. 1 through 6, the buffer was 0.045 $\mathrm{M}$ with respect to succinate. In Exps. 7 and 8 , the buffers contained $0.05 \mathrm{M}$-succinic acid and c. $0.09 \mathrm{M}$-tris or triethylamine.

$\dagger$ To obtain thermal inactivation curves, $0.5 \mathrm{ml}$. samples were heated at $59^{\circ}$ and after cooling the samples, activity was measured as usual using $0.04 \mathrm{~m}-\mathrm{Na}$ succinate as the assay buffer (in Exp. 7, tris-succinate buffer was used for assay).

$\ddagger$ Extract dialyzed (at $c .5^{\circ}$ ) against water for $5 \mathrm{hr}$.; the tyrosinase was activated by this treatment and the dialyzed extract showed a slight pink colour.

not only activates $T^{\mathrm{s}}$ tyrosinase but also stabilizes the enzyme markedly with respect to thermal inactivation. On the other hand, in the presence of certain nitrogenous bases the enzyme is fully activated but is very heat labile. In comparison with the organic bases, $\mathrm{K}^{+}$has some stabilizing influence and judging from Exp. 4 it appears that $\mathrm{Na}^{+}$can significantly increase the halflife in the presence of relatively large amounts of $\mathrm{K}^{+}$. Preactivation of $\mathrm{T}^{\mathrm{s}}$ tyrosinase by heating at $59^{\circ}$ for $1.5 \mathrm{~min}$. did not appreciably affect the thermostabilities in sodium, potassium, and triethylamine-succinate buffers.

Table 3. Thermostability of partially purified $\boldsymbol{T}^{L}$ and $\boldsymbol{T}^{s}$ tyrosinases at $59^{\circ}$ in sodium and potassium phosphate buffers at $\mathrm{pH} 6$

\begin{tabular}{|c|c|c|c|c|}
\hline \multirow[b]{2}{*}{ Exp. } & \multirow[b]{2}{*}{ Buffer } & \multirow[b]{2}{*}{ Conc.* (M) } & \multicolumn{2}{|c|}{ Half-life at $59^{\circ}$ (min.) } \\
\hline & & & $\mathbf{T}^{\mathbf{L}}$ & $\mathbf{T}^{\mathbf{s}}$ \\
\hline 1 & Water & - & c. 0.5 & c. 2 \\
\hline 2 & Sodium phosphate & $0 \cdot 04$ & - & 51 \\
\hline $\mathbf{3}$ & Sodium phosphate & 0.08 & $3 \cdot 5$ & 67 \\
\hline 4 & Sodium phosphate & $0 \cdot 16$ & - & 140 \\
\hline 5 & Sodium phosphate & 0.80 & 19.0 & 120 \\
\hline 6 & Potassium phosphate & 0.04 & - & 7 \\
\hline 7 & Potassium phosphate & 0.08 & c. 0.5 & 14 \\
\hline 8 & Potassium phosphate & $0 \cdot 16$ & c. 1 & 28 \\
\hline 9 & Potassium phosphate & 0.40 & 3 & - \\
\hline 10 & Potassium phosphate & $0 \cdot 80$ & 6 & 75 \\
\hline
\end{tabular}

For these experiments, the organisms were grown and the tyrosinases extracted as described by Horowitz \& Fling (1953). The enzymes were purified by their procedure and then dialyzed against $0.05 \mathrm{M}$-potassium phosphate $\mathrm{pH} 6$.

* Final concentration of added phosphate; note that due to the dialysis, c. 0.01 m-potassium phosphate was introduced with the enzyme preparation (see $\dagger$ ).

+ To obtain thermal inactivarion rates, $0.5 \mathrm{ml}$. samples (consisting of $0.1 \mathrm{ml}$. enzyme and $0.4 \mathrm{ml}$. buffer) were heated at $59^{\circ}$ and after cooling the samples, activity was measured as usual using 'mixed' $0 \cdot 1 \mathrm{~m}$-phosphate pH 6 (see Methods) as the assay buffer. 
Crude $T^{L}$ tyrosinase showed qualitatively similar behaviour with respect to stabilization by $\mathrm{Na}^{+}$, i.e., typical half-lives observed in sodium and potassium succinate buffers were 3 and $\mathbf{0 . 5} \mathrm{min}$., respectively.

The effects of sodium and potassium ions on the thermostability of partially purified $\mathbf{T}^{\mathrm{L}}$ and $\mathbf{T}^{\mathrm{S}}$ tyrosinases in phosphate buffer $\mathrm{pH} 6$ are shown in Table 3. As with the crude enzymes, the thermostability of the fractionated preparations was greatly enhanced by $\mathrm{Na}^{+}$. It is evident that $\mathrm{K}^{+}$, at comparable concentrations, was much less effective, and also that the half-life of both $\mathbf{T}^{\mathrm{u}}$ and $\mathbf{T}^{\mathrm{s}}$ tyrosinases can be appreciably lengthened by increasing the buffer concentration.

\section{DISCUSSION}

Activation of tyrosinase has been previously observed in preparations from grasshopper eggs (Bodine, Tahmisian \& Hill, 1944), Drosophila melanogaster larvae (Ohnishi, 1953), and Drosophila adult flies (Horowitz \& Fling, 1955). Other reports have also suggested the existence of a 'protyrosinase' which can be activated by heating in Neurospora crassa (Horowitz \& Shen, 1952; Schaeffer, 1953; Fox \& Burnett, 1956) and in the ascomycete Gelasinospora tetrasperma (Boulter, 1957). Activation of tyrosinase and other copper oxidases can also be effected by various chemical agents, e.g., the grasshopper enzyme (Bodine et al. 1944) is activated by urea and certain detergents, while ascorbic acid oxidase (Frieden \& Maggiolo, 1957) is activated by a variety of substances (proteins, amino acids, thyroxine analogues, etc.) which in general possess the ability to chelate copper. $\mathrm{Al}^{+++}$and several divalent cations also appear to activate the latter enzyme (Frieden \& Maggiolo, 1957). The present experiments indicate that Neurospora tyrosinase is activated by certain organic nitrogenous bases, which may act through interaction with the copper moiety of the enzyme, and also by $\mathrm{Na}^{+}$. In connexion with the sodium ion effect, it is of interest that a significant binding of $\mathrm{Na}^{+}$(and $\mathrm{K}^{+}$) by several proteins has recently been observed (Carr, 1956; Lewis \& Saroff, 1957) and that the activity of a number of enzymes is markedly enhanced by $\mathrm{Na}^{+}$or $\mathrm{K}^{+}$(e.g. salivary amylase, Schneyer, 1952; Rotini \& Galoppini, 1952-53; $\beta$-galactosidase, Landman, 1957; pyruvic phosphoferase, Kachmar \& Boyer, 1953). Considering the diversity of agents which share the ability to activate copper oxidases and the complex nature of these catalysts (Mallette \& Dawson, 1949; Mason, 1956) it seems likely that several different mechanisms may be involved in the activation phenomenon. This conclusion is supported by the observation that thermal activation of Neurospora tyrosinase appears to be irreversible, while the activation by $\mathrm{Na}^{+}$or urea is readily reversible.

Stabilization of enzyme activity, with respect to thermal inactivation, by various cations has been frequently observed (e.g. with salivary amylase, Schneyer, 1952, Rotini \& Galoppini, 1952-53; and with trypsin, Crewther, 1953), and the present data demonstrate that the thermostability of Neurospora crassa tyrosinase also is strongly influenced by the ionic environment. In this regard, it should be noted that $\mathrm{Na}^{+}$activates the enzyme and exerts a 
marked stabilization effect, whereas tris (buffer) and triethylamine, which also activate, do not protect against thermal inactivation.

Thus far, attempts to demonstrate significant differences between the $\mathrm{T}^{\mathbf{8}}$ and $\mathrm{T}^{\mathrm{L}}$ Neurospora crassa tyrosinases, other than with respect to thermostability, have been unsuccessful (Horowitz \& Fling, 1956a). Both enzymes appear to be similar with regard to the activation phenomenon, but they do show quantitative differences with respect to stabilization by $\mathrm{Na}^{+}$and $\mathrm{K}^{+}$. It is probable that these differences are due to modifications in the structural organization of the enzyme in the two strains.

This work was done while one of us (H. G.) was a Public Health Service Research Fellow of the National Cancer Institute, United States Public Health Service; on leave (1956-57) from the Department of Microbiology, Western Reserve University School of Medicine, Cleveland, Ohio, U.S.A.

\section{REFERENCES}

Bodine, J. H., Tahmisian, T. N. \& Hill, D. L. (1944). Effect of heat on protyrosinase. Heat activation, inhibition, and injury of protyrosinase and tyrosinase. Arch. Biochem. 4, 403.

Boulten, D. (1957). The oxidases of Gelasinospora tetrasperma in relation to the endogenous respiration. J. gen. Microbiol. 16, 305.

Carr, C. W. (1956). Studies on the binding of small ions in protein solutions with the use of membrane electrodes. VI. The binding of sodium and potassium ions in solutions of various proteins. Arch. Biochem. Biophys. 62, 476.

Crewther, W. G. (1953). The effect of $\mathrm{pH}$ and cations on the thermal denaturation of trypsin. Aust. J. biol. Sci. 6, 597.

Dawson, C. R. \& TARPley, W. B. (1951). Copper oxidases. In The Enzymes, vol. II, part 1, p. 454, ed. by J. B. Sumner and K. Myrbäck. New York: Academic Press Inc.

Fox, A. S. \& Burnett, J. B. (1956). The kinetics of protyrosinase activation in Neurospora crassa, Strain 15300. Genetics, 41, 643.

Frieden, E. \& Maggiolo, I. W. (1957). Activation and other properties of ascorbic acid oxidase. Biochim. biophys. Acta, 24, 42.

Horowitz, N. H. \& FliNG, M. (1953). Genetic determination of tyrosinase thermostability in Neurospora. Genetics, 38, 360.

Honowitz, N. H. \& Fling, M. (1955). The autocatalytic production of tyrosinase in extracts of Drosophila melanogaster. In Amino Acid Metabolism, p. 207, ed. by W. D. McElroy and B. Glass. Baltimore: The Johns Hopkins Press.

Horowitz, N. H. \& Fling, M. (1956a). The role of the genes in the synthesis of enzymes. In Enzymes: Units of Biological Structure and Function, p. 139, ed. by O. H. Gaebler. New York: Academic Press Inc.

Horowitz, N. H. \& Fling, M. (1956 b). Studies of tyrosinase production by a heterocaryon of Neurospora. Proc. nat. Acad. Sci., Wash. 42, 498.

Horowitz, N. H. \& Shen, S-C. (1952). Neurospora tyrosinase. J. biol. Chem. 197, 513.

KaChmar, J. F. \& Boyer, P. D. (1953). Kinetic analysis of enzyme reactions. II. The potassium activation and calcium inhibition of pyruvic phosphoferase. J. biol. Chem. 200, 669.

Landman, O. E. (1957). Properties and induction of $\beta$-galactosidase in Bacillus megaterium. Biochim. biophys. Acta, 23, 558.

Lewis, M. S. \& Saroff, H. A. (1957). The binding of ions to the muscle proteins. Measurements on the binding of potassium and sodium ions to myosin $\mathbf{A}$, myosin B, and actin. J. Amer. chem. Soc. 79, 2112. 
Mallette, M. F. \& Dawson, C. R. (1949). On the nature of highly purified mushroom tyrosinase preparations. Arch. Biochem. 23, 29.

Mason, H. S. (1956). Structures and functions of the phenolase complex. Nature, Lond. 177, 79.

OHNIsHI, E. (1953). Tyrosinase activity during puparium formation in Drosophila melanogaster. Japan. J. Zool. 11, 69.

Rotini, O. T. \& Galoppini, C. (1952-53). L'influenza del cloruro di sodio sull'optimum di temperatura dell'amilasi salivare. Enzymologia, 15, 279.

SchaEFFER, P. (1953). A black mutant of Neurospora crassa. Mode of action of the mutant allele and action of light on melanogenesis. Arch. Biochem. Biophys. 47, 359 .

Schneyer, L. H. (1952). The effect of sodium and potassium ions on the temperature behaviour of salivary amylase. Arch. Biochem. Biophys. 39, 65.

(Received 9 July 1957) 